\title{
A Framework to Optimize Production Planning in the Vaccine Industry
}

\author{
Néjib Moalla ${ }^{1.2}$, Abdelaziz Bouras' and Gilles Neubert ${ }^{1}$ \\ 1 CERRAL/LIESP IUT Lumière Lyon 2 \\ 160 Boulevard de l'Université, 69500, Bron, France \\ \{Nejib.Moalla, Abdelaziz.Bouras, Gilles.Neubert\}@univ-lyon2.fr, \\ WWW home page: http://iutcerral.univ-lyon2.fr/CERRAL/ \\ 2 Sanofi Pasteur/Campus Mérieux \\ 1541, Avenue Marcel Mérieux 69280, Marcy-L'étoile, France \\ Nejib.Moalla@SanofiPasteur.com, \\ WWW home page: http://www.sanofipasteur.com/
}

\begin{abstract}
.
In the literature, production planning optimization works are widely approached by mathematical researches to integrate more data and constraints toward delivering more reliable plans. In the particular context of vaccine industry, the vaccine product is a molecular substance with diverse definitions and presentations that involve with the closely coordination of many actors in the company. When it is difficult to support planning process by optimization solution, our contribution in this paper consists of proposing a production planning framework to structure some data integration issues according to different planning levels. With the correspondence of a better data management among production planning process, we aim to decline some best practices to provide more stable and reliable plans.
\end{abstract}

\section{Introduction}

The vaccine industry evolved under the control of permanent and strict regulations imposed by health and regulatory authorities such as WHO (http://www.who.int/) and FDA (http://www.fda.gov/) in the USA or AFSSAPS in France, etc. These regulations aim at structuring the product development and production processes to avoid unexpected incidents with the respect of the diversity of product definitions (biological, viral, chemical and operational). When approximately $12 \%$ of the sold volumes convey $82 \%$ of incomes, the Winner-take-all strategy implies that defining a leading product guarantees the long term profitability. In this context, the production planning is a complex and multi-factorial process, impacted by the organisation of manufacturing process, the market tendency, the specifications of 
health authorities, regulation authorities and maybe other vaccine industries.

We present in the next section some specifications of product in the vaccine industry. In the third section, we deal with the production planning process and the limitations of MRP II concepts. We propose in the fourth section a production planning framework to structure some data integration issue to optimize the planning process. Finally, we present some planning best practices to provide more stable and reliable plans.

\section{The vaccine industry}

The specificity of vaccine industry dominates in the particular definition of its product, the vaccine $[1,2]$. At the production stage, we can only control the manufacturing process and not the product itself. Indeed, the biological aspect of the active substances in the vaccines differs from product in the chemical industry (pharmaceutical industry) by a very complex structure. The biological production consists of a mixture of molecular substances not always well identified. This specificity makes the control procedures, already different from one product to another, more delicate than complex.

\subsection{The vaccine product}

Along its lifecycle, a vaccine passes by two huge stages: the vaccine design and the industrial production [3].

\subsubsection{Vaccine design}

The development of a new vaccine presents a long term action that rapidly exceeds 10 years (Fig. 1). Starting from exploring phase, researchers look for new substances being able to contribute to the creation of a vaccine against a given disease. If a vaccine candidate emerges from the discovery research, preclinical tests allow its characterization for a better control of its behavior to generate the appropriate antigens.

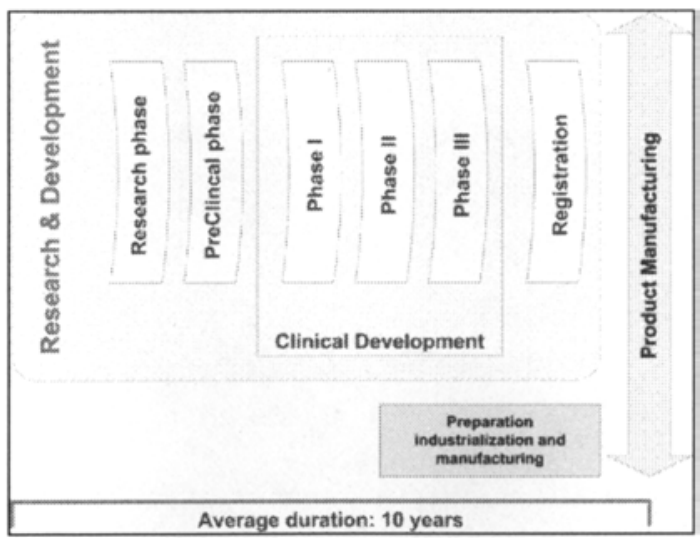

Fig. 1. Vaccine design 
In clinical tests stage, several phases allow to better characterize the product by testing an increasing number of patients to determine the effectiveness, the safety and the harmlessness of the vaccine with the suitable intervals of injections. All information concerning clinical reports, tests, and control results are capitalized throughout these phases. To prove the reproductiveness and industrial capability, three consistency batches are manufactured.

Finally, to produce and market this new vaccine, it is necessary to prove to the health authorities (WHO http://www.who.int, FDA in the USA http://www.fda.gov/, etc) the utility of the vaccine $[4,5]$. This passes by the submission of Marketing Authorization (MA) request to the health authority of destination country. The MA contains all information collected during the process of research and development. Once the product is approved, it can be manufactured and distributed inside this country.

\subsubsection{Vaccine production}

The vaccine production is a rather complex process during from 6 months to 2 years. The production process, done by fixed batch size, passes by several states. For each state, we identify 3 tasks, the manufacturing, the quality control and the batch release. We can divide all manufacturing states into two great steps: biological manufacturing and pharmaceutical manufacturing (Fig. 2).

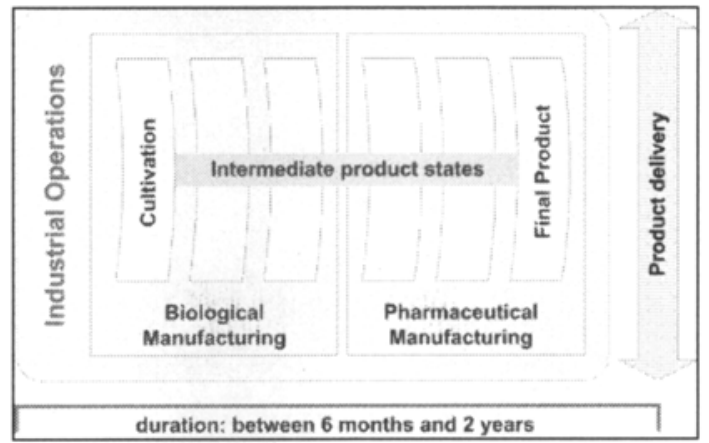

Fig. 2. Vaccine manufacturing

Biological manufacturing: covers from the vaccine valence manufacturing state until the final active substance state (monovalent) using production specificities retained and presented in the MA.

Pharmaceutical manufacture: consists in the mixture of active substances, their distribution in the appropriate dosage forms (syringe, blister, etc.) until the packaging. These operations must respect the sterility conditions, quality of air, quality of the final product, etc; all of them are specified in the MA.

Considering the complexity of the biological definition of the vaccine and the large quantity of data to define it, the management of the product data presents a big challenge in this context. In the vaccine design stage, product data are generally manually written data, so it's very complex to analyze these data and use them in other information systems like the ERP. In this context, we are interesting in explaining the production planning process and presenting some ways to improve it. 


\section{Production planning in vaccine industry}

\subsection{The integration of ERP systems}

As an Enterprise Inwards Solution, ERP systems [6, 7] cover an intra-enterprise integration of various functions based on MRP II concepts with the added functionalities of finance, distribution and human resources development, integrated to handle the global business needs of a networked enterprise. In the particular context of vaccine industry, our scope covers the production planning process and deals with products complexity as well as different information required to provide reliable production plans according to MRP II concepts. At each generated plan, we identify an objective, a horizon and a detail level.

\subsection{Limitation of MRP II based systems}

When we analyze MRP II concepts, we identify some limitations $[8,9,10]$ that prevent from providing reliable and realistic plans at different planning levels. We report that:

- The lead time not only needs to be pre-specified but also is assumed to be static over the entire planning horizon.

- The capacity is assumed to be infinite, which means the derived production planning may not be realized.

- Even derived plans are realizable in each planning level; they are not optimized due to the lack of coherence between them. The synchronization actions can change considerably defined plans.

- The production system is made nervous. Little adjustment in MPS changes the due date, requiring the recalculation of MRP.

Vaccine industry is suffering from these limitations due to the specificities of product and market inputs. As examples, the quality control process of some product components can takes unpredictable periods of time according to production process maturity. Defined plans must be frequently reviewed when capacity changes. Furthermore, face to some pandemic diseases, a vaccine company must adjust their production plans with these new priorities.

For optimization purposes, new methods are developed for production planning. Some of them are based on mathematical programming as Linear Programming (LP) [11] - the most widely used methods -, Dynamic Programming (DP) [12] - for multi-periods planning - or Stochastic Programming (SP) [13] - coping with the uncertainty -.

Generally, planning and scheduling jointly determine how, when, and in what quantity products will be manufactured or purchased. In essence, planning establishes what should be done and scheduling determines how to do it.

Optimization actions cover especially the tactical production planning because planning models are more abstract than scheduling models. The idea is that in planning, we want to look a bit more at the forest than the trees. We want to use a model that is abstract enough to be manageable, yet contains enough detail to be realistic.

Advanced Planning and Scheduling (APS) [14] is a software system based on 
mathematical technologies like linear programming, genetic algorithms, heuristics or constraint based programming (CBP). It uses intelligent analytical tools to perform finite scheduling and produce realistic plans. APS systems are able to generate plans and schedules very quickly. APS covers various capabilities such as "finite capacity scheduling" or "constraint-based scheduling" at shop floor level.

Due to the complexity of vaccine product definition, the huge volume of data managed and the number parameters to configure, it is very difficult to adopt an APS solution to support and optimize production planning in the vaccine industry. Tim Peakman et al present in [15] what APS systems can bring, if they will be adapted to support vaccine industry specifications. We look so for some more adapted ways to improve production planning with existent MRP II based system.

Next, we aim to define a planning framework to structure the complexity of product in the production planning process by structuring different information impacting production plans.

\section{Production planning framework}

Due to the complexity of vaccine product, the limitations of MRP II concepts, and the inability to deploy an APS solution, we propose to analyze production planning process in the vaccine industry and provide all information necessary to obtain reliable and stable plans. Following planning concepts in different MRP II levels, we choose in this work to spend more efforts in data management by improving data integration than approaching capacity management.

\subsection{Integration of static data}

Static data in the ERP refer to all the data needed to define products and infrastructures. In the planning process, it is very important de validate technical data of product, bill of materials, takings, etc. This validation is made with the implication of all concerned company instances. When defined in the ERP, data need to usually updated, validated, coherent and especially compliant with regulatory constraints specified in the Marketing Authorizations [16].

\subsection{Integration of demand and forecast data}

The integration and the projection of demands and forecasts at different planning levels are based on defined static data. Following MRP II concepts, dynamic data are generated and a special effort needs to be spent to optimize the scheduling of created planning orders, working orders, and purchasing orders.

In the particular context of vaccine industry, the aggregation of demand by product family to generate tactic plans and after, the projection by final product when generating MPS plans, presents a complex task due to regulatory aspect of the vaccine product. This specificity affects product composition when we need to reuse some components in different products and in batch release process when we should track the destination of each component batch. 
The codification of demands and forecasts according to the local production information system specificities in the company refer to production data integration problems presented in [17].

\subsection{Integration of Supply chain data}

In a supply chain scope, there are many information systems in coordination with the ERP. The same data can be defined and managed in different information systems. In the planning process, we need to use data collected from all supply chain sources. These data correspond for example to the component batch size. This parameter is defined in the Marketing Authorization (MA) for the monovalent solution state and calculated then validated by producer for following the product states. Finally, all batch size data are collected in the ERP system to be used in the MRP process.

\subsection{Production planning framework}

We propose to structure some elements related to previous data integration issues according to different planning levels in MRP II concepts. We aim with the reviewing of these elements to improve the operational level and reduce the gap between defined plans and achieved plans.

Table 1. Production planning framework in vaccine industry

\begin{tabular}{|c|c|c|c|}
\hline Planning levels & Static data & $\begin{array}{l}\text { Demands and } \\
\text { forecasts data }\end{array}$ & Supply chain data \\
\hline $\begin{array}{l}\text { Strategic } \\
\text { planning }\end{array}$ & $\begin{array}{l}\text { Definition of generic data } \\
\text { for planning }\end{array}$ & Market study & $\begin{array}{l}\text { Development of new } \\
\text { product (R\&D) }\end{array}$ \\
\hline $\begin{array}{l}\text { Tactic planning } \\
\text { (S\&OP) }\end{array}$ & $\begin{array}{l}\text { Definition of product } \\
\text { family technical data }\end{array}$ & $\begin{array}{l}\text { Demand } \\
\text { aggregated by } \\
\text { product family }\end{array}$ & $\begin{array}{l}\text { Common product } \\
\text { family specifications } \\
\text { (business units) }\end{array}$ \\
\hline $\begin{array}{l}\text { Operational } \\
\text { Planning (MPS) }\end{array}$ & $\begin{array}{l}\text { Integration of detailed } \\
\text { technical data (i.e. BOM, } \\
\text { all item data, etc.) }\end{array}$ & $\begin{array}{l}\text { Demand at final } \\
\text { product level }\end{array}$ & $\begin{array}{l}\text { Product specifications } \\
\text { for a given destination } \\
\text { (regulatory affairs) }\end{array}$ \\
\hline $\begin{array}{l}\text { Detailed MRP } \\
\text { explosion } \\
\text { calculus }\end{array}$ & $\begin{array}{l}\text { Validation of technical } \\
\text { data }\end{array}$ & $\begin{array}{l}\text { Demand at } \\
\text { component level: } \\
\text { Component reuse }\end{array}$ & \\
\hline CRP & Theoretical capacity & & $\begin{array}{l}\text { Observed capacity } \\
\text { (producer) }\end{array}$ \\
\hline Scheduling & $\begin{array}{l}\text { Coherence of technical } \\
\text { data (i.e. component lead } \\
\text { time according to takings } \\
\text { lead time) }\end{array}$ & $\begin{array}{l}\text { Demand at } \\
\text { operation level }\end{array}$ & $\begin{array}{l}\text { Shop floor adjustment } \\
\text { (quality assurance) }\end{array}$ \\
\hline $\begin{array}{l}\text { Execution and } \\
\text { feedbacks }\end{array}$ & & & $\begin{array}{l}\text { Batch release (product } \\
\text { quality \& quality } \\
\text { management) }\end{array}$ \\
\hline
\end{tabular}




\section{Discussion}

The vaccine market is very sensitive to new pandemics and imposes reactivity to vaccine industries in order to provide the market with needed vaccine. Defined plans are permanently excited by new events reported by new regulations, new demands or new incidents at the manufacturing stage. Basing on the different elements identified in the planning framework, we suggest some best practices to adopt in planning process to provide more reliable plans.

The validation of static data presents the first condition to provide reliable plans. Due to regulatory specifications, data are not always entirely defined in the ERP system. So, even product data are valid in the ERP, they cannot be from the regulatory point of view. Through different planning levels, product data must be coherent between product states in the BOM, takings, etc. A permanent effort must be made to ensure data compliance according to regulatory restrictions, data coherence through product states and throughout planning process levels.

The integration of dynamic data update defined plans at periodic intervals. At each update, there are both, a vertical integration of new data at different plans and we need a special effort to synchronize new plans, and a horizontal integration and we need additional effort to coordinate new plans. It is frequently to observe the same global volume but not the same values inside plans. Moreover, smoothing action is not always suited due to component shelf life and regulatory restrictions when chosen facilities. Also, many products use the same components in different BOM levels. The final products do not depend closely of the same MA. So, it is essential to track component batches after their release until their destination to be sure that regulatory restrictions are respected.

During the production process, many services in the company have to interact to deliver the right product with the predefined quality at the right moment. Throughout the planning process, some transverse actions must be done between these services to validate together defined plans and enhance the opportunity to reach the planned objectives. Some balanced scorecards would help to assess the level of coordination between $R \& D$, production, quality and regulation.

\section{Conclusion}

We cover in this paper the scope of production planning in the vaccine industry. We describe first the specificities of the vaccine product and we highlight after the limitations of MRPII concepts and the inability of Advanced Planning and Scheduling (APS) systems to support and optimize the planning process in vaccine industry. To pass these limitations, we propose to improve the data management issue by a better integration a static data, demands \& forecasts and other supply chain data that can affect the planning process. The structuring of these data integration issues according to different planning levels in a planning framework throws some improvement topics. Finally, by developing these topics, we propose some best practices toward improving the stability and the reliability of generated plans. We aim furthermore to structure these best practices in some standard working 
procedures to be shared by all company actors.

\section{Acknowledgment}

This work is elaborated with the collaboration of Sanofi Pasteur France company where Mr. Néjib MOALLA is integrated as a researcher in Industrial Operations services during his $\mathrm{PhD}$ thesis (CIFRE N 865/2005).

\section{Bibliography}

I FDA report, Challenge and opportunity on the critical path to new medical products, U.S. Food and Drug Administration, March 2004, $31 \mathrm{p}$.

2 FDA final report, Pharmaceutical CGMPs for the 21 st century - a risk-based approach, U.S. Food and Drug Administration, September 2004, 29p.

3 E. Salinsky and C. Werble, The vaccine industry: Does it need a shot in the arm?, National Health Policy Forum, Background Paper, January 25, 2006, 34 p.

4 C. Grace, Global health partnership impact on commodity pricing and security, DFID Health Resource, 2004, 22p.

5 S. Thaul, Vaccine policy issues for the $108 \mathrm{~h}$ congress, The library of Congress, Order code RL31793, updated May 22, 2003, l6p.

6 P. Kelle andA. Akbulut, The role of ERP tools in supply chain information sharing, cooperation, and cost optimization, Int. J. Production Economics 93-94, 2005, p.41-52.

7 V. Martin, Software component architecture in supply chain management, Computers in Industry, Volume 53, Issue 2, February 2004, p 165-178.

8 A. Hatchuel, D. Saidi-Kabeche and J.C. Sardas, Towards a new planning and scheduling approach for multistage production systems, International Journal of Production Research, Volume 35, Issue 3 March 1997, p 867-886.

9 Y. Chang and D. McFarlane, Supply Chain Management Using Auto-ID Systems, Book chapter in Evolution of Supply Chain Management, Copyright 2004, ISBN 978-1-4020-7812-5 (Print), part 3, p 367. 392.

10 T. Wuttipornpun and P. Yenradee, Development of finite capacity material requirement planning system for assembly operations, Production Planning \& Control, Volume 15, 2004, p 534-549.

11 R.C. Wang and T.F. Liang, Application of fuzzy multi-objective linear programming to aggregate production planning, Computers and Industrial Engineering, Volume 46, Issue I (March 2004), p17 - 41.

12 B. Srinivasan, S. Palanki and D. Bonvin, Dynamic optimization of batch processes: Characterization of the nominal solution, Computers and Chemical Engineering 27 (2003), p 1-26.

13 N.V. Sahinidis, Optimization under uncertainty: state-of-the-art and opportunities, Computers and Chemical Engineering 28 (2004), p $971-983$.

14 H.O. Günther, D.C. Mattfeld and L. Suhl, Supply Chain Management and Advanced Planning Systems: A Tutorial, book chapter in Supply Chain Management und Logistik, Copyright 2005, ISBN 978-3-7908-1576-4 (Print), p 3-40.

15 T. Peakman, S. Franks, C. White and M. Beggs, Delivering the power of discovery in large pharmaceutical organizations, Drug Discovery Today Vol. 8, No. 5 March 2003, 9 pages.

16 N. Moalla, A. Bouras, G. Neubert, Y. Ouzrout and N. Tricca, Data Compliance in Pharmaceutical Industry, Interoperability to align Business and Information Systems, ICEIS 2006, International Conference on Enterprise Information Systems, PAPHOS, CYPRUS. 23 - 27, May 2006, pp. 79-86.

17 N. Moalla, A. Bouras and Y. Ouzrout, Production Data Integration in the Vaccine Industry, 5th International Conference on Industrial Informatics, Austria, 23 - 27, July 2007, (accepted). 